Galimkair Mutanov - Sayabek Ziyadin - Askhat Serikbekuly

\title{
APPLICATION OF SYSTEM-DYNAMIC MODELING TO IMPROVE DISTRIBUTION LOGISTICS PROCESSES IN THE SUPPLY CHAIN
}

This article presents an approach of improve logistics processes with the system dynamics modeling of two different processes scenarios. System dynamics is used, not only as a causal loop diagram, but calculated measures of end-user satisfaction indicators were provided by experts, as well.

Literature review of fundamental definitions and recent ideas in subject of supply chain management (SCM), system dynamics (SD), business processes model and notation (BPMN) and distribution logistics for dozens of major sources, has been made.

In the work, methods of expert interviews, content analysis of recent publications, system-dynamic modeling and business process modeling, were used. Developed BPMN-models of distribution logistics business processes are given in Appendices \#1 and \#2.

Keywords: distribution logistics, system dynamics, BPMN, supply chain, modelling

\section{Introduction}

Logistics is the process of planning, managing and implementing efficient and powerful flows, and storing goods and related information from the point of departure to the point of consumption, the purpose of which is to satisfy customer needs [1].

I. Gros [2] defines logistics as the planning, management and execution of goods flows, starting from development and purchase through production and distribution in accordance with the end customer, so that all the market requirements are met with minimal costs and capital expenditures.

According to Straka [3], logistics is a system in which there is an effect on elements in order to coordinate material, information and financial flows, as a result of which the customer's requirements are accordingly met and the corresponding economic effect is ensured.

As can be seen from the above definitions, one of the key objectives of logistics is to ensure the satisfaction of end consumers.

Importance of ensuring the customer satisfaction is also confirmed in the SCOR model (Supply Chain Operations Reference-model), proposed by the international organization - The Supply Chain Council (SCC), one of the five main attributes of which is response.

A response is the speed at which tasks are performed. The speed at which the supply chain delivers products to the customer [4].

Kazakhstan's wholesale companies, which are elements of the supply chain of consumer goods, especially small and medium ones, cannot always ensure full compliance with the above principles and goals of logistics, due to insufficient resources to improve the quality of service, dynamically changing needs of their customers and other complex factors. The task of supply chain management, according to Ivanov et al. [5], in this case is to provide a quick response to market changes and customer needs, while reducing the costs.

In order to successfully apply the supply chain management strategy in their activities, companies must first carefully analyze their current activities and identify the main weaknesses, eliminating which can ensure a higher speed and quality of service delivery and increase the level of the customer satisfaction. One of the effective ways to carry out such an analysis can be business processes modeling in the company. Modeling processes by describing actions and measuring the results of their processes allows organizations to constantly analyze them, thereby contributing to their improvement [6].

Business process management, according to [7] helps organizations to achieve their strategic goals through analysis, modeling, implementation, execution, control and continuous improvement of processes, which leads to increased productivity, increased innovation and quality.

In the process of modeling existing and proposed business processes in companies, the Business Process Model and Notation (BPMN 2.0) [8] was used - the most popular notation of business process modeling today.

Sterman [9] also emphasizes that modeling is an iterative, ongoing process for testing and validating 
models. Experiments in the virtual world determine the design and execution of experiments in the real world; in turn, experience in the real world leads to changes and improvements in the virtual world and in mental models [9].

According to Tolujew [10], the main purpose of modeling is to obtain numerical estimates of performance indicators in the system under consideration for such modes that have not yet been observed in reality. Continuous models based on differential equations as models of system dynamics are the most often used to reproduce production and logistics processes [11].

To determine the most effective scenario, which allows ensuring end-user satisfaction in the distribution chain of consumer goods, the system-dynamic modeling approach was applied. In the role of the end consumer for the company in the distribution chain, this article considers an independentdelivery point. Two process models in the BPMN 2.0 notation, which are considered in the work, act as scenarios of the system-dynamic model.

\section{Literature review}

\subsection{Supply chain management}

The term "supply chain management" (SCM) was first proposed by Oliver and Weber [12]. Oliver defined supply chain management as the process of planning, implementing and controlling the operations of the chain with the purpose to satisfy customer requirements as efficiently as possible. The SCM spans all the movements and storage of raw materials, work-in-progress inventory, and finished goods from point of origin to point of consumption [13].

Based on Chen et al. [14], Christopher [15], Harrison [16], managing a new type of logistics system called the supply chain in terms of minimizing total costs, increasing profits, improving customer service and reducing the impact of uncertainty on the system is called the chain management supplies [17].

Van Leeuwen and Tijssen [18] say that the supply chain management concept combines the tasks of various disciplines: logistics (minimizing costs in the supply chain), operational management (efficient inventory and production management), marketing (focus on creating values for the client) and market relationships (interaction with partners in the supply chain).

Akhmetkalieva [17] calls the concept of the supply chain management one of the most effective ways of managing commercial structures, which can significantly improve business optimization and help synchronize all the ypes of activities performed during production and distribution; optimization of added value for the end user; eliminate inefficient business activities. Currently, one of the main goals of the supply chain management concept is to optimize the entire system, which will achieve higher quality of service at lower overall costs, and not only maximize the productivity and profitability of individual business units of the chain [17].
Ivanov et al. [19] expressing their opinion based on the works of Sheffi and Rice [20], Tomlin [21], Wilson [22], Klibi et al. [23], Hahn and Kuhn [24], Simchi-Levi and Wei [25], Baghalian et al. [26], called the main problems in supply chain management uncertainty and dynamics, which require an understanding of the effectiveness of the supply chain from a dynamic point of view as part of efficiency and flexibility / sustainability.

The modern concept of supply chain management, in addition to maximizing the level of service and minimizing costs, is complemented by the need to ensure flexibility and sustainability of the supply chainin the face of increasing environmental problems and limited resources [5].

\subsection{Distribution logistics}

Distribution logistics is an integral and one of the most important components of the entire supply chain. There are various definitions that describe the essence of distribution logistics.

Ihde [27] suggests that distribution logistics deals with issues related to temporal and spatial related transfers of real goods and among the systems of labour division.

Distribution logistics is responsible for all warehouse and transport movements of goods for consumers and related information, management and control of activities [28].

Distribution logistics, as stated by DHL Logbook [29], includes all types of activities related to the provision of finished goods for the client, which can be sent to the client immediately after their production, to a warehouse for further processing or, if necessary, to other regional distribution warehouses.

Distribution logistics should provide the most appropriate way to analyze, select and implement all the activities, as well as strategic and other decisions related to the provision of products to the client in such a way as to achieve error-free market activity [3].

A detailed definition of distribution logistics is described by Kappauf et al. [30], who describe it as a business process for selling goods, including delivery, transportation to the customer and subsequent billing. It links the production logistics of the company (and/or its external procurement department in the case of goods produced from outside) with the requirements (orders) of customers. The main objective of distribution logistics is the efficient provision of goods for customers according to established criteria, such as quantity, time and price (p. 171).

In general, distribution logistics plays an important role both at the strategic level, determining the sales policy, the distribution network structure of the company, regions of distribution of the product, the location of system elements, methods of order processing and at the tactical level, determining the most efficient use of resources in building warehouses and buying and the use of necessary equipment for storage and transportation of goods, types of vehicles, etc. [31]. 
Based on the presented definitions and opinions of various authors regarding distribution logistics, its importance is obvious not only in the logistics processes of the company, but also in general for the company's activities, its successful development and gaining an attractive position in the market.

\subsection{System dynamics}

System dynamics was founded back in the late 1950s at the Massachusetts Institute of Technology under the direction of J Forrester [32]. In 1961, Forrester published the first classic book, which set out the concept of system dynamics, which is a direction in the study of complex systems, exploring their behavior over time and depending on the structure of system elements and the interaction between them, including causal relationships, feedback loops, reaction delays, environmental influences and others [33].

In part, system dynamics is a method for developing and testing formal mathematical models and computer modeling of complex nonlinear dynamic systems; it has much in common with other modeling methods [9].

Sterman [9] describes the key principles that must be considered when building models for the successful application of system dynamics:

A model should be created to solve a specific, existing rather than abstract problem;

1. The model needs to be integrated into the project at the very beginning of its implementation - the existing problem should be identified before the start of the project, based on past experience of the company;

2. The model must be constantly tested;

3. The main attention should be paid to the most significant, key elements of the model and not to focus on the details [9].

Importance of considering the project as a holistic system within the framework of the system dynamics methodology, without focusing on details and operations, was discussed by Rodrigues and Bowers [34].

According to Bendoly E. [35], the system dynamics methodology emphasizes the importance of considering the interaction and development of system elements, as well as providing a structured analytical image of processes.

Mutanov et al. [36] call the system dynamics methodology, which allows modeling complex systems at a high level of abstraction, without taking into account small details, the basis of an intelligent information system.

The methodology of the system-dynamic modeling is widely used in various fields of activity. Examples of the application of system dynamics can serve as the work of Sterman [9] - in building a car leasing strategy, Mutanov et al. [36] - in making investment decisions, Uehara et al [37] - in the study and modeling of ecological and economic systems, Ivanov et al. [19] in the modeling and analysis of the supply chain, Tama et al. [38] - to optimize profits in the network of supplies of vegetable products and many others.
Distribution logistics usually crosses borders between organizations and an understanding of incentives and organizational barriers is a prerequisite for the successful application of any "scientific" solution [39], which also confirms the validity of applying the system dynamics methodology in modeling distribution logistics processes.

\subsection{BPMN 2.0}

Business Process Model and Notation (BPMN) a system of conventions (notation) and their descriptions in XML for modeling business processes, which provides companies the opportunity to understand their internal business procedures in graphical notation and makes it possible to transfer these procedures in a standard way [8].

In addition, graphical notation will facilitate understanding of the interaction of productivity and business transactions between organizations. This ensures that enterprises will understand themselves and their business participants and will allow organizations to quickly adapt to new internal conditions and B2B business conditions [8].

The BPMN 2.0 is the latest, most relevant version of notation to date, which is widely used in modeling business processes

Effectiveness of using this method in process modeling is confirmed by Bisogno et al. [40], where they say that the analysis of business processes using the BPMN notation can help to identify and correct the corresponding operating problems.

The BPMN is the leading language for noting business process modeling and allows business analysts and managers to increase the efficiency and quality of processes and performs the main function of modeling business processes - presenting processes so that the current process can be analyzed and improved in the future [41].

The advantage of the BPMN is that it is accessible to a wide range of users in the company - from analysts who create process diagrams and developers responsible for implementing business process execution technology, to managers and ordinary users who manage these business processes and monitor their implementation. Thus, the BPMN aims to bridge the gap between business process models and their implementation [42].

\section{Methods and materials}

The research object is a small and medium-sized production and wholesale trading companies of Kazakhstan, distributing goods to independent retail stores (delivery point). These retail stores, as the final consumer for the company in the chain of distribution of fast moving consumer goods (FMCG), are considered in this article. The subject of the study is the business process of receiving and processing an order from a delivery point by small 
Table 1 Input data for scenario No. 1 of the system-dynamic model

\begin{tabular}{|c|c|c|c|}
\hline Process step name & $\begin{array}{l}\text { Time of } \\
\text { execution, } \\
\text { working hours }\end{array}$ & $\begin{array}{l}\text { Time of waiting before } \\
\text { previous process step, } \\
\text { working hours }\end{array}$ & Probability, \% \\
\hline Visiting a delivery point by a sales agent & 0.00 & 0.00 & 100 \\
\hline Reception and agreement of a DP's order by a sales agent & 0.17 & 0.03 & 88 \\
\hline Possible adjustments by the sales agent to the order & 0.08 & 0.00 & 43 \\
\hline Transfer of an order by a sales agent to an accountant / operator & 0.08 & 0.00 & 100 \\
\hline Reception of order by operator from a sales agent & 0.08 & 4.00 & 100 \\
\hline $\begin{array}{l}\text { The operator checks the availability of goods in the warehouse and } \\
\text { overdue receivables at the DP }\end{array}$ & 0.02 & 0.08 & 100 \\
\hline $\begin{array}{l}\text { Notification by the operator of the DP if there is a debt or shortage of } \\
\text { goods in the warehouse }\end{array}$ & 0.08 & 0.00 & 3 \\
\hline $\begin{array}{l}\text { Registration by the operator of the order and preparation of } \\
\text { accompanying documents (invoice) }\end{array}$ & 0.03 & 0.00 & 100 \\
\hline The operator transfers the order to the warehouse to form & 0.00 & 0.00 & 100 \\
\hline Collection and order confirmation & 0.08 & 0.00 & 100 \\
\hline $\begin{array}{l}\text { Correction, if necessary, accompanied by the coordination of } \\
\text { adjustments with the DP }\end{array}$ & 0.08 & 0.00 & 3 \\
\hline $\begin{array}{l}\text { Determination of transport for delivery of the order, printout of route } \\
\text { and loading lists }\end{array}$ & 0.02 & 0.00 & 100 \\
\hline $\begin{array}{l}\text { Transfer of the order to the forwarder, accompanied by the transfer of } \\
\text { the necessary documents and information }\end{array}$ & 0.01 & 0.00 & 100 \\
\hline Forwarder receiving goods and documents from the warehouse & 0.01 & 0.00 & 100 \\
\hline Delivery of goods to the DP & 0.08 & 0.00 & 100 \\
\hline Transferring an order to an DP & 0.08 & 0.03 & 96 \\
\hline $\begin{array}{l}\text { Acceptance of payment and receipt of signed documents (invoice) } \\
\text { depending on the financial conditions of cooperation with the point and } \\
\text { payment }\end{array}$ & 0.02 & 0.00 & 67 \\
\hline $\begin{array}{l}\text { Transfer of payment and signed documents (invoice) to the operator / } \\
\text { accountant to complete the process. }\end{array}$ & 0.02 & 0.00 & 67 \\
\hline Total duration per one order (in case of all events) & 0.95 & 4.143 & \\
\hline Probability-adjusted duration per one order & 0.71 & 4.139 & \\
\hline $\begin{array}{l}\text { Total average duration of the process, taking into account expectation } \\
\text { and probability* }\end{array}$ & \multicolumn{3}{|c|}{4.85} \\
\hline
\end{tabular}

*average duration of the process, taking into account expectation and probability for the client - delivery point

and medium-sized manufacturing and wholesale trading companies of Kazakhstan

In the process of modeling the existing and proposed business process diagrams, the BPMN 2.0 was used a system of conventions and their descriptions in XML for modeling business processes [8].

Models in the BPMN 2.0 are used as the data source with two alternative scenarios for the system dynamic model.

In the process of modeling the distribution chain between companies and retail outlets, its main elements and the interaction between them, the system-dynamic modeling method was used [33].

The Ventana Systems' simulation software "VenSim" was used for the system dynamics modelling and Microsoft Visio 2016 for modelling processes in the BPMN 2.0 standard.
The following indicators were used as input data for calculating the order processing time for each of the scenarios of the system-dynamic model:

- duration of the process - the time that each steptakes;

- waiting time - the time between the steps of the process;

- probability - the probability of a specified process event occurring.

All the indicators taken as the basis of the calculations were obtained as a result of an expert interview and are the average values of the data of experts from their real experience.

Results of this expert interview are also described in the work of Mutanov and Serikbekuly [43].

In the framework of this work, the following basic terms were adopted:

- Delivery point (DP) - a retail outlet selling goods to consumers; 
Table 2 Input data for scenario No. 2 of the system-dynamic model

\begin{tabular}{|c|c|c|c|}
\hline Process step name & $\begin{array}{l}\text { Time of } \\
\text { execution, } \\
\text { working hours }\end{array}$ & $\begin{array}{l}\text { Time of waiting } \\
\text { before the previous } \\
\text { process step, working } \\
\text { hours }\end{array}$ & Probability, \% \\
\hline Visiting a delivery point by a sales agent & 0.00 & 0.00 & 0 \\
\hline Reception and agreement of a DP's order by a sales agent & 0.00 & 0.00 & 0 \\
\hline Possible adjustments by the sales agent to the order & 0.00 & 0.00 & 0 \\
\hline Transfer of an order by a sales agent to an accountant/operator & 0.00 & 0.00 & 0 \\
\hline Reception of order byoperator from a sales agent & 0.00 & 0.00 & 0 \\
\hline $\begin{array}{l}\text { The operator checks the availability of goods in the warehouse and } \\
\text { overdue receivables at the DP }\end{array}$ & 0.00 & 0.00 & 0 \\
\hline $\begin{array}{l}\text { Notification by the operator of the DP if there is a debt or shortage of } \\
\text { goods in the warehouse }\end{array}$ & 0.00 & 0.00 & 0 \\
\hline $\begin{array}{l}\text { Registration by the operator of the order and preparation of } \\
\text { accompanying documents (invoice) }\end{array}$ & 0.00 & 0.00 & 0 \\
\hline The operator transfers the order to the warehouse to form & 0.00 & 0.00 & 100 \\
\hline Collection and order confirmation & 0.08 & 0.00 & 100 \\
\hline $\begin{array}{l}\text { Correction, if necessary, accompanied by the coordination of } \\
\text { adjustments with the DP }\end{array}$ & 0.00 & 0.00 & 0 \\
\hline $\begin{array}{l}\text { Determination of transport for delivery of the order, printout of route } \\
\text { and loading lists }\end{array}$ & 0.02 & 0.00 & 100 \\
\hline $\begin{array}{l}\text { Transfer of the order to the forwarder, accompanied by transfer of the } \\
\text { necessary documents and information }\end{array}$ & 0.01 & 0.00 & 100 \\
\hline Forwarder receiving goods and documents from the warehouse & 0.01 & 0.00 & 100 \\
\hline Delivery of goods to the DP & 0.08 & 0.00 & 100 \\
\hline Transferring an order to an DP & 0.08 & 0.03 & 96 \\
\hline $\begin{array}{l}\text { Acceptance of payment and receipt of signed documents (invoice) } \\
\text { depending on the financial conditions of cooperation with the point and } \\
\text { payment }\end{array}$ & 0.02 & 0.00 & 67 \\
\hline $\begin{array}{l}\text { Transfer of payment and signed documents (invoice) to the operator/ } \\
\text { accountant to complete the process. }\end{array}$ & 0.02 & 0.00 & 67 \\
\hline Total duration per one order (in case of all events) & 0.32 & 0.030 & \\
\hline Probability-adjusted duration per one order & 0.30 & 0.029 & \\
\hline $\begin{array}{l}\text { Total average duration of the process, taking into account expectation } \\
\text { and probability }\end{array}$ & \multicolumn{3}{|c|}{0.33} \\
\hline
\end{tabular}

- $\quad$ Sales agent (SA) - a representative of a trading company that periodically visits and receives orders from retail outlets (delivery points).

The numerical indicators, used in the model for calculating scenario No. 1 (the existing process), are shown in Table 1

Details of the process steps:

- duration of the process of visiting a delivery point and duration of waiting are equal to zero, since it represents the moment the employee arrives at the point and has a $100 \%$ probability, due to the fact that it is the initial link in the entire process of receiving an order;

- reception and agreement of the order takes an average of 10 minutes and has a waiting time of about 2 minutes. The expectation may be due to presence of buyers, sales agents of other companies or delivery of goods from other companies at the time of the visit;
- making adjustments can take 10 minutes and does not have a waiting time, as it occurs immediately after receiving an order from a point in $50 \%$ of cases;

- the transfer of the order to operator takes 10 minutes, as it includes the transfer of information on all the commodity items and quantities for each, does not have a waiting time and is a mandatory process $(100 \%$ probability);

- reception of order by the operator takes 5 minutes, has a $100 \%$ probability and the average waiting time is 4 hours, given that this step of the process is carried out in parallel for many orders;

- checking the availability of goods and debt takes an average of 1 minute and is carried out using the accounting system, has a waiting time of 5 minutes and a probability of $100 \%$;

- notification of the DP in the absence of goods or the 
Table 3 Matching lead time and customer (DP's) satisfaction

\begin{tabular}{ccc}
\hline Order processing time,working hours & Level of satisfaction \\
\hline 1 & 5 & 5 \\
5 & 3 & 4 \\
8 & 2 \\
13 & 1 \\
\hline
\end{tabular}

presence of debt may take 5 minutes, waiting time $=0$, probability $3 \%$ - the process is quite rare;

- $\quad$ placing an order and preparing documents takes 2 minutes, does not have a waiting time and is always carried out;

- the process of transferring an order to the warehouse has a duration of zero, since this process is carried out for all orders for the day at the same time and not for each separately;

- collection and confirmation of the order in the warehouse takes about 5 minutes;

- adjustment of the order when collecting it in the warehouse can take 5 minutes and is carried out quite rarely - in about $3 \%$ of cases;

- determination of transport for order delivery takes a short period of time - about 1 minute;

- the transfer of the order to the forwarder and its acceptance by the forwarder are also very short-term steps with a duration of approximately 30 seconds each, since it consists of loading the order into transport;

- delivery of the order to the DP has an average duration of 5 minutes, which is calculated taking into account the average number of freight forwarder orders per day, equal to 30 and the length of the working day;

- transferring an order to a point of sale takes 5 minutes, while waiting, as in the case of the process of receiving an order by a sales agent, lasting 2 minutes on average may be due to the presence of buyers, sales agents or forwarders of other companies at the point at the time of order transfer. The probability of this process is $95 \%$, since provided that the DP has a type of payment in cash, but does not pay for the order upon delivery, the forwarder does not leave the order and returns the goods to the warehouse;

- acceptance of payment and documents from the DP can take about a minute and is carried out in 50\% of cases, which depends on the type of financial conditions for the DP (cash/cashless/consignment);

- transfer of payment and documents by the forwarder to the cash desk also takes 1 minute and has a 50\% probability, which is confirmed by the conditions described in the previous paragraph.

The numerical indicators, used for scenario No. 2 (the proposed process scheme), are shown in Table 2.

The key difference between scenarios is that the first eight steps of the process have zero indicators (execution time, waiting time and probability). This difference is provided by the using of a different online-services by trade companies. An important condition for the successful application of the second scenario is availability and use of a warehouse reservation system in a trading company. It will allow the delivery point to see the actual availability of goods in the warehouse of the supplier company.

It also excludes the step of adjusting the order and coordinating it with the point of sale when collecting at the warehouse, since the point cannot initially place an order in which there will be commodity items that are not in stock.

Otherwise, the steps of the process, including the duration of their fulfillment and expectations, as well as the probability, remain unchanged. The main indicator of the level of customer satisfaction (delivery points) is a processing time of the order - the period from the moment the order is received until delivery to the point.

The final satisfaction score is a score from 1 to 5 , where 5 is the best indicator and 1 is the worst indicator. The assessment depends on the processing time of the order and this compliance is shown in Table 3

This correlation of the level of satisfaction with the processing time of the order was compiled on the basis of experimental data obtained by the author from experts in the wholesale industry. The basis of the correspondence between the values of the duration of order processing and customer satisfaction was the Fibonacci sequence.

\section{Results and discussion}

Based on the data obtained by Mutanov and Serikbekuly [43], on the structure of the process of receiving and processing orders in small and medium-sized wholesale trading companies of Kazakhstan, obtained as a result of a field study by expert interviews and as a continuation of this study and more and a detailed description and study of this process, modeling of the process of receiving and processing orders between participants in the studied supply chain was carried out.

The authors identified a standard scheme used by most of the studied production and wholesale trading companies in Kazakhstan. The process diagram in the BPMN 2.0 notation is presented in Appendix 1.

As can be seen in Appendix 1, the process of receiving and processing an order consists of a large number of steps and is accompanied by many approvals and the transfer of data and documents at its various steps.

The process includes 5 participants, the main roles and functions of which are described in Table 4. 
Table 4 Functions and roles of participants in the process of receiving and processing an order

\begin{tabular}{cl}
\hline Participant role & \multicolumn{1}{c}{ Main role function } \\
\hline Delivery point & $\begin{array}{l}\text { gives the initial order, confirms it, expects, accepts, pays for this order, signs } \\
\text { the supporting documents } \\
\text { visits the point, accepts the order, communicates with the point on all issues } \\
\text { (debts, balances, marketing campaigns, fulfillment of plans, legal relations), } \\
\text { transfers the order to operator, makes adjustments to the order } \\
\text { accepts an order from the merchant, checks the availability of goods and debts, } \\
\text { prepares accompanying documentation, transfers the order to warehouse, } \\
\text { monitors and accepts payment from the merchant/forwarder } \\
\text { marehouse Manager }\end{array} \quad \begin{array}{l}\text { acceptance, assembly and loading of an order } \\
\text { Foceives goods and documents, delivers the order to the point, receives } \\
\text { payment and supporting documents, transfers payment to the cashier }\end{array}$ \\
\hline
\end{tabular}

In the majority of the small and medium-sized trading companies in Kazakhstan today, as shown in Appendix 1, the process consists of such main steps as:

1. Visiting a delivery pointby a sales agent

2. Reception and agreement of a DP's order by a sales agent

3. Possible adjustments to the order by the sales manager

4. Transfer of an order by a sales agent to an accountant / operator

5. Reception of order by operator from a sales agent

6. The operator checks availability of goods in the warehouse and overdue receivables at the DP

7. Notification by the operator of the DP if there is a debt or shortage of goods in the warehouse

8. Registration by the operator of the order and preparation of accompanying documents (invoice)

9. The operator transfers the order to the warehouse for picking goods for delivery

10. Collection and confirmation of the order with possible adjustment if necessary, accompanied by the coordination of adjustments with the point of sale (subject to the availability of goods in the accounting system, but its actual absence in the warehouse)

11. Determination of transport for delivery of the order, printout of route and loading lists

12. Transfer of the order to the forwarder, accompanied by the transfer of the necessary documents and information

13. Forwarder receiving goods and documents from the warehouse

14. Delivery of goods to the DP

15. Transferring an order to an DP

16. Acceptance of payment and receipt of signed documents (invoice) depending on the financial conditions of cooperation with the point and payment

17. Transfer of payment and signed documents (invoice) to the operator/accountant to complete the process.

As can be seen, the process contains many tasks, complicated by the need for approvals at various steps, which significantly increases its duration and also contains great risks of making mistakes and inaccuracies during the transfer of order information and documents at some steps.
The authors propose a more effective process of interaction with the DP, presented in Appendix 2.

The main improvement of the proposed interaction scheme, in comparison to the existing one at the moment, is the exclusion of a sales representative from the process, which automatically reduces a significant number of process steps previously performed by this participant. The exclusion of these steps from the process is ensured by use of a company information system that automatically performs these actions. Examples of such systems can be class systems: CRM (Customer Relationship Management), SFA (Sales Force Automation), OMS (Order Management System).

This change brings benefits such as:

1. Reduced costs of maintaining sales representatives

2. Reduced order lead time

3. Eliminated need to coordinate the order at the acceptance step, since the point makes the order on its own.

The next difference is the exclusion from the process of confirming the availability of goods in the warehouse, since this information is available at the initial checkout of the delivery pointand it is impossible to order the missing goods. This improvement is suitable for those companies in the information system of which there is a reservation system for orders - in this case, other agents and points will not be able to book the same product and the delivery pointwill receive its order. Accordingly, the steps of adjustment and confirmation of the order by the DP are also excluded from the process.

The operator's task of placing an order and creating related documents is not available in the information system, since upon receipt of an order from a point of sale these actions can be performed by the program.

Changes and improvements after applying the proposed business process scheme occur not only in the composition of the participants and in the number of steps, but also in the methods of transferring and storing information:

1. Order data now comes into the system directly from the source, without going through several participants, which eliminates the risk of loss or distortion of this information. 


\section{Unique Order's} Execution Time 4

\section{Time WeightedAverage By Probability of events in the process}

\section{Probability of events in process}
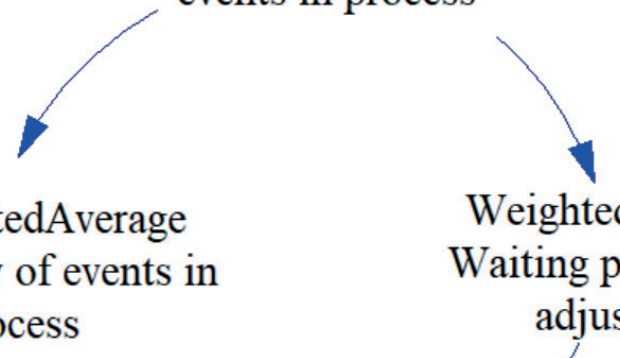

Unique Order's Waiting Time

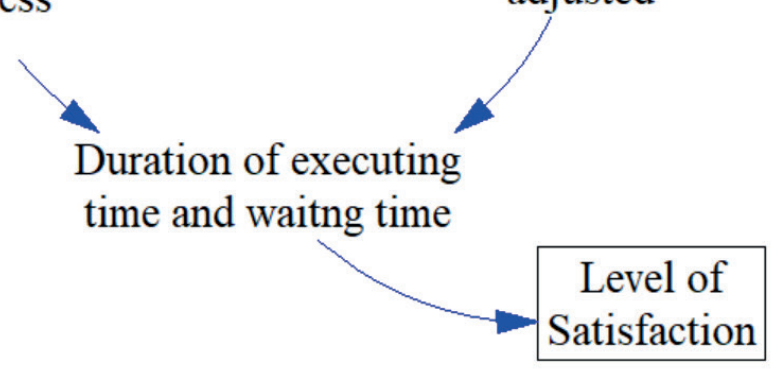

Figure 1 System dynamic model for the two business process scenarios of order management in the distribution chain

Table 5 Results of comparison of the two scenarios

\begin{tabular}{ccc}
\hline & Time and speed & Level of satisfaction \\
\hline Scenario \#1 & 4.85 & 3 \\
Scenario \#2 & 0.33 & 5 \\
\hline
\end{tabular}

2. The format for providing the forwarder with a routing sheet is changing. Now there is no need to compile and print it. The route sheet, which is created by the system, is available for the forwarder in the mobile application. This not only reduces the time it takes to compile, print and transmit, but also ensures maximum efficiency when creating the most optimal routes for the system, as well as flexible and quick adjustment of the route sheet by the system during the delivery process when the route actually changes.

3. The need for transmitting information to the forwarder about the availability of debt and the financial conditions of the DP- all this information is also available to him in the mobile application in real time. As one can see from the comparison results, implementation of the proposed business process scheme for receiving and processing orders in a trading company greatly simplifies one of its most basic and significant business processes, improves its quality, reliability and efficiency, reduces the labor costs, and the most importantly the implementation of the process reduces the length of the cycle, because this indicator can be considered one of the key, since the speed and timeliness of fulfillment of obligations to the client, especially for small and medium enterprises' trade is of a great importance for the formation of positive and long-term relationship with the client and his loyalty to the company.

The importance of reducing such an indicator as the duration of the cycle is also confirmed by the fact that the companies that are considered are directly involved in distribution of the FMCG that are of paramount importance to the end consumers, respectively, ensuring the timely availability of these goods in the required volume is also of social significance.

In the VenSim program, a system-dynamic model was calculated (Figure 1) according to the two described scenarios.

Based on results of the modeling processes and comparing their scenarios in dynamics, the results of each scenario were summarized in Table 5 .

As one can see from results shown in Table 5, the level of satisfaction and time spent on one execution of one order are improving. Particularly noticeable is improvement in the speed of order completion from 4.85 to 0.33 working hours.

\section{Conclusion}

Results of the study show an improvement in the speed indicators, and accordingly, satisfaction with the quality of logistics services due to implementation of the proposed scheme (Appendix 2).

The practical significance of the work is in the fact that the simulation results in the form of business process scenarios can be applied in creating and optimization of processes in real trading companies or distribution chains using information systems for managing the class orders:

- CRM (Customer Relationship Management),

- SFA (Sales Force Automation), 
- $\quad$ OMS (Order Management System).

One example is ezapp.kz, popular among Kazakhstani trading companies, an online service designed to automate the process of accepting and processing orders.

Note that application of the proposed process scenario and use of the proposed tools would not be effective for absolutely all wholesale companies in Kazakhstan. There are such companies, processes, which have certain features and specifics and require a more thorough and individual approach to improving the organization of the process of receiving and processing orders.

To build a complete and high-quality supply chain model, one needs very accurate and detailed data for each individual supply chain process and each individual company. Receiving and processing an order is one of the important processes that were already carefully analyzed. Continuing the modeling of other logistics processes using the proposed methodology, it is possible to build a single complete model of the complete supply chain.

Further areas of application and development of this research are the trade "digital twin" as a combination of process and dynamic models into a single synchronized one. This will require obtaining actual data from information systems for order management of companies in the entire supply chain in real time. Given development of IoT, BPMS and RPA technologies - this approach seems possible at the moment.

Additional benefits of implementing online supply chain management are:

- improving the quality of customer service,

- the provision of additional services due to ability to monitor the movement of goods,

- reduction of paper operations,

- reduction of labor costs at each automated section of logistics processes.

\section{References}

[1] Council of Logistics Management. 1961

[2] GROS, I. Logistika ano ci ne? / Logistics yes or not? (in Czech). Logistika, MesicnikHospodarskychNovin.1995, 3, p. 58. ISSN 1213-7693.

[3] STRAKA, M. Logistika distribuce. Ako efektivne dostat vyrobok na trh / Logistics distribution. How to effectively get the product on the market (in Slovak). Ruzomberok: EPOS, 2013. ISBN 9788056200155.

[4] Supply Chain Council [online]. 2019. [Viewed 2019-11-15]. Available from: http://www.apics.org/

[5] IVANOV, D., TSIPOULANIDIS, A., SCHONBERGERB, J. Operations and supply chain strategy. In: Global supply chain and operations management [online]. Springer, Cham: Springer Texts in Business and Economics. 2017. ISBN 978-3-319-24215-6, eISBN978-3-319-24217-0. Available from: https://doi.org/10.1007/978-3-319-24217-0_4

[6] PEREIRA, M. F., JACOBSEN, A. L., BIANCHI, I. S., MORITZ, G. O. Modelo de producao de material didatico: ouso da notacao BPMN emcurso a distancia / Model for production of teaching material: the use of BPMN notation in distance learning courses (in Portuguese). RAI Revista de Administracao e Inovacao. 2011, 8(4), p. 45-66. ISSN 1809-2039. Available from: https://doi.org/10.5773/rai.v8i4.898

[7] MINONNE, C., TURNER, G. Business process management - are you ready for the future? Knowledge and Process Management [online]. 2012, 19(3), p. 111-120. eISSN1099-1441. Available from:https://doi.org/10.1002/kpm.1388

[8] OMG. Business Process Modeling and Notation (BPMN). Version 2.0 [online]. 2019. Available from: http://www.bpmn.org/

[9] STERMAN, J. Business dynamics, systems thinking and modeling for a complex world. Boston: Irwin/McGraw-Hill, 2000.

[10] TOLUJEW, J. Graphic method for modeling material flows in supply chains. The Journal of Economic Research and Business Administration. 2018, 126(4), p. 170-178. ISSN 1563-0358, eISSN2617-7161.

[11] REGGELIN, T., TOLUJEW, J. A mesoscopic approach to modelingand simulation of logistics processes. In Winter Simulation Conference: proceedings. IEEE, 2011. ISBN 978-1-4577-2108-3, p. 1513-1523

[12] OLIVER, R. K., WEBBER, M. D. Supply-chain management: logistics catches up with strategy. Outlook, Booz, Allen \& Hamilton, Inc, 1982. Reprinted in: CHRISTOPHER, M. G. Logistics: the strategic issue. London: Chapman and Hall, 1992, p. 63-75.

[13] POUNDER, P., BOVELL, G., PILGRIM - WORELL, S. A Review of supply chain management and its main external influential factors. Supply Chain Forum [online]. 2013, 14(3), p. 42-50. ISSN 1625-8312, eISSN1624-6039. Available from: https://doi.org/10.1080/16258312.2013.11517320

[14] CHEN, F., FEDERGRUEN, A., ZHENG, Y. S. Coordination mechanisms for a distribution system with one supplier and multiple retailers. Management Science [online]. 2001, 47(5), p. 693-708. ISSN 1526-550. Available from: https://doi.org/10.1287/mnsc.47.5.693.10484

[15] CHRISTOPHER, M. The agile supply chain: competing in volatile markets. Industrial Marketing Management [online] 2000, 29(1), p. 37-44. ISSN 0019-8501. Available from: http://dx.doi.org/10.1016/S0019-8501(99)00110-8 
[16] HARRISON, A. Logistics Management and Strategy: Competing through the Supply Chain. 4 ed. Financial Times/ Prentice Hall, 2010, p. 384. ISBN 978-0273730224.

[17] AKHMETKALIEVA, S. K. The concept of supply chain management as a method of optimizing the doing business. The Journal of Economic Research and Business Administration [online]. 2018, 123(1), p. 4-11. ISSN 1563-0358, eISSN2617-7161. Available from: https://be.kaznu.kz/index.php/math/article/view/1938

[18] VAN LEEUWEN T., TIJSSEN, R. Interdisciplinary dynamics of modern science: analysis of crossdisciplinary citation flows. Research Evaluation [online]. 2000, 9(3), p. 183-187. ISSN 0958-2029, eISSN1471-5449. Available from: https://doi.org/10.3152/147154400781777241

[19] IVANOV, D., SOKOLOV, B., DOLGUI, A. The Ripple effect in supply chains: trade-off "efficiency - flexibility-resilience" in disruption management. International Journal of Production Research [online]. 2014, 52(7), p. 2154-2172. ISSN 0020-7543, eISSN 1366-588X. Available from: https://doi.org/10.1080/00207543.2013.858836

[20] SHEFFI, Y., RICE, J. B. A supply chain view of the resilient enterprise. MIT Sloan Management Review [online]. 2005, 47(1), p. 41-48. ISSN 1532-9194. Available from: https://sloanreview.mit.edu/article/a-supply-chain-view-of-the-resiliententerprise/

[21] TOMLIN, B. On the Value of mitigation and contingency strategies for managing supply chain disruption risks. Management Science [online]. 2006, 52, p. 639-657. Available from: https://be.kaznu.kz/index.php/math/article/ view/2039

[22] WILSON, M. C. The impact of transportation disruptions on supply chain performance. Transportation Research Part E: Logistics and Transportation Review [online]. 2007, 43, p. 295-320. ISSN 1366-5545. Available from: https://doi.org/10.1016/j.tre.2005.09.008

[23] KLIBI, W., MARTEL, A., GUITOUNI, A. The design of robust value-creating supply chain networks: A critical review. European Journal of Operational Research [online]. 2010, 203(2), p. 283-293. ISSN 0377-2217. Available from: https://doi.org/10.1016/j.ejor.2009.06.011

[24] HAHN, G.J., KUHN, H. Value-based performance and risk management in supply chains: A robust optimization approach. International Journal of Production Economics [online]. 2012, 139(1), p. 135-144. ISSN 0925-5273, eISSN1873-7579. Available from: https://doi.org/10.1016/j.ijpe.2011.04.002

[25] SIMCHI-LEVI, D., WEI, Y. Understanding the performance of the long chain and sparse designs in process flexibility. Operations Research [online]. 2012, 60, p. 1125-1141. ISSN 0030-364X, eISSN 1526-5463. Available from: https://doi.org/10.2307/23323684

[26] BAGHALIAN, A., REZAPOUR, S., FARAHANI, R. Z. Robust supply chain network design with service level against disruptions and demand uncertainties: a real-life case. European Journal of Operational Research [online]. 2013, 227(1), p. 199-215. ISSN 0377-2217. Available from: https://doi.org/10.1016/j.ejor.2012.12.017

[27] IHDE, G. B. Distributions - Logistik / Distribution logistics (in German). Stuttgart, New York: Gustav Fischer Verlag, 1978. ISBN 3437400517.

[28] SCHULTE, CH. Logistik / Logictic (in German). Munchen: Vahlen, 1991. ISBN 9783800614547.

[29] DHL Logbook [online]. 2013. Available from: http://www.dhldiscoverlogistics.com/cms/en/course/processes/ distribution_logistics/definition.jsp

[30] KAPPAUF, J., LAUTERBACH, B., KOCH, M. Logistic core operations with SAP [online]. Verlag Berlin Heidelberg: Springer, 2011. ISBN 978-3-642-18203-7, eISBN978-3-642-18204-4. Available from: https://doi.org/10.1007/978-3-64218204-4

[31] STRAKA, M. The position of distribution logistics in the logistic system of an enterprise. Acta Logistica- International Scientific Journal about Logistics [online]. 2017, 4, p. 23-26. ISSN 1339-5629. Available from: https://doi.org/10.22306/ al.v4i2.5

[32] FORRESTER, J.W. Industrial dynamics - a major breakthrough for decision makers. Harvard Business Review [online]. 1958, 36(4), p. 37-66. ISSN 0017-8012. Available from: https://doi.org/10.1225/58404

[33] FORRESTER, J.W. Industrial Dynamics. Cambridge: MIT Press, 1961. ISBN 9780262060035.

[34] RODRIGUES, A., BOWERS, J System dynamics in project management: a comparative analysis with traditional methods. System Dynamics Review [online]. 1996, 12(2), p. 121-139. eISSN1099-1727. Available from: https://doi.org/10.1002/(SICI)1099-1727(199622)12:2<121::AID-SDR99>3.0.CO;2-X

[35] BENDOLY, E. Systems dynamics understanding in projects: information sharing, psychological safety, and performance effects. Production and Operations Management [online]. 2014, 23(8), p. 1352-1369. eISSN1937-5956. Available from: https://doi.org/10.1111/poms.12024

[36] MUTANOV, G., MILOSZ, M., SAXENBAYEVA, Z. H., KOZHANOVA, A. Investments decision making on the basis of system dynamics. In: Modern approaches for intelligent information and database systems. SIEMINSKI, A., KOZIERKIEWICZ, A., NUNEZ, M., HA, Q.-T. (eds.) [online]. Springer International Publishing AG, part of Springer Nature, 2018, p. 293-303. Available from: https://doi.org/10.1007/978-3-319-76081-0_25 
[37] UEHARA, T., NAGASE, Y., WAKELAND, W. Integrating economics and system dynamics approaches for modelling an ecological-economic system. Systems Research and Behavioral Science [online]. 2016, 33, p. 515-531. eISSN 1099-1743. Available from: https://doi.org/10.1002/sres.2373

[38] TAMA, I.P., AKBAR, Z., EUNIKE, A. Implementation of system dynamic simulation method to optimize profit in supply chain network of vegetable product. IOP Conference Series: Materials Science and Engineering. 2017, 337(1), 012014. ISSN 1757-8981, eISSN1757-899X. Available from: https://doi.org/10.1088/1757-899X/337/1/012014

[39] BRANDIMARTE, P., ZOTTERI, G. Introduction to distribution logistics. John Wiley \& Sons, 2007, ISBN 978-0-471-750-44-4.

[40] BISOGNO, S., CALABRESE, A., GASTALDI, M., GHIRON, N. L. Combining modelling and simulation approaches: how to measure performance of business processes. Business Process Management Journal [online]. 2016, 22(1), p. 56-74. ISSN 1463-7154. Available from: https://doi.org/10.1108/BPMJ-02-2015-0021

[41] ALMEIDA, L.C., SALLES, S.A.F., CARVALHO, R.L., MORAIS, A.S.C., SILVA, S.V. S. BPMN e ferramentas da qualidade para melhoria de processos: um estudo de caso. GEPROS / BPMN and quality tools for process improvement: a case study (in Portuguese). GEPROS. Gestao da Producao, Operacoes e Sistemas [online]. 2019, 14(4), p. 156-175. eISSN1984-2430. Available from: https://doi.org/10.15675/gepros.v14i4.2308

[42] VLASOV, A.I., GONOSHILOV, D. S. Simulation of manufacturing systems using BPMN visual tools. Journal of Physics Conference Series [online]. 2019, 1353:012043. ISSN 1742-6588, eISSN1742-6596. Available from: https://doi.org/10.1088/1742-6596/1353/1/012043

[43] MUTANOV, G. M., SERIKBEKULY, A. (2019). Fast reengineering for distribution logistic processes in small companies in Kazakhstan based on graphical and system dynamic model. 34th International Business Information Management Association Conference, IBIMA 2019 : proceedings. 2019. ISBN 978-0-9998551-3-3.

\section{Appendix 1}

The scheme of receiving and processing an order used by trading companies is available online at: http://journals.uniza.sk/data/MutanovEtAl/Appendix1.vsdx

\section{Appendix 2}

The proposed scheme of the business process of receiving and processing orders is available online at: http://journals.uniza.sk/data/MutanovEtAl/Appendix2.vsdx 